\title{
IMPROVEMENT IN THE COLD STORAGE OF APHIDIUS ERVI (HYMENOPTERA : APHIDIINAE)
}

\author{
ISABELLE FRÈRE ${ }^{1 *}$, CAROLE BALTHAZAR ${ }^{1}$, AHMED SABRI2* \\ AND THIERRY HANCE ${ }^{1}$ \\ ${ }^{1}$ Earth and Life Institute, Université catholique de Louvain, Biodiversity Research Centre, Croix du Sud, 4-5, 1348 Louvain-la-Neuve, \\ Belgium, Tel (+32) 104734 96, Fax (+32) 10473490 \\ ${ }^{\star}$ Corresponding author: isabelle.frere@uclouvain.be \\ ${ }^{2}$ Centre Wallon de Biologie Industrielle, Université de Liège, Boulevard du Rectorat 29, B40 Sart-Tilman, 4000 Liège, Belgium \\ *Corresponding author: a.sabri@ulg.ac.be
}

\section{ABSTRACT}

Biological control is beginning to be more commonly used, especially in greenhouses. The inundatory release of insects, especially parasitoids, requires a thorough knowledge of their biology and of mass-rearing techniques. Moreover, to synchronize releases with host presence, the parasitoids have to be kept in cold storage. However, cold storage may lead to a decrease in the viability of the parasitoids, in particular their survival, mobility and sex ratio. The aim of this study was to determine the best temperature at which to keep parasitoid mummies in cold storage. The parasitoid Aphidius ervi Haliday (Hymenoptera, Braconidae) and two of its host aphids, Sitobion avenae and Acyrthosiphon pisum, were used. It is concluded that the mummies can be kept for a maximum of two weeks at $7^{\circ} \mathrm{C}$ without emergence of adults and for seven weeks at $2{ }^{\circ} \mathrm{C}$ without emergence or mortality. Moreover, storage of the mummies at 7 or $2^{\circ} \mathrm{C}$ does not affect fertility. However, parasitoid pupae in A. pisum mummies suffered a higher mortality and took longer to complete their development. The practical implications of these results are discussed.

Keywords: aphid parasitoids, cold storage

\section{Introduction}

Biological control is beginning to become more widely used, especially in greenhouses. The inundatory release of insects, especially parasitoids, requires a thorough knowledge of their biology and of mass-rearing techniques. However, cold storage of parasitoids can lead to a decrease in their viability, in particular in their survival, mobility and sex ratio (Langer and Hance 2000; Sigsgaard 2000; Colinet et al. 2006; Ismail et al. 2010).

Aphidius ervi is a solitary hymenopteran koinobiont endoparasitoid, which parasitizes a wide range of aphid species (Stilmant et al. 2008). It is already commonly used for biological control and is mainly marketed for the control of Aulacorthum solani and Macrosiphum euphorbiae. In Belgium, this parasitoid is recorded in the field when the temperature reaches $15^{\circ} \mathrm{C}$ and above. Moreover, it becomes active at temperatures over $8^{\circ} \mathrm{C}$ (walking) or $9^{\circ} \mathrm{C}$ (flying). Its parasitic ability diminishes as the temperature drops, but its lower temperature threshold for egg-laying is $2{ }^{\circ} \mathrm{C}$ (Langer et al. 2004; Sigsgaard 2000) and at low temperatures, a higher proportion of the offspring is male (Langer et al. 2004).

Various studies have determined the lower temperature threshold for development of $A$. ervi, which is between 2.2 and $6.8^{\circ} \mathrm{C}$ and depends on the host aphid and laboratory conditions (Campbell et al. 1974; Sigsgaard 2000; Malina and Praslicka 2008).

A. ervi mummies survive storage for long periods at temperatures close to $0{ }^{\circ} \mathrm{C}$ (Michel 2007). The host aphid in this case was Acyrthosiphon pisum. The percentage survival decreases the longer they are kept at a low tem- perature and as temperature is decreases. Thus, it is possible to store mummies of aphids containing $A$. ervi at temperatures below $0{ }^{\circ} \mathrm{C}$. The losses reported are due in part to the effects of cold, but also desiccation and starvation. Indeed, the survival of mummies is dependent on their lipid reserves and water content. At low temperatures, they develop more slowly and the period for which they can survive increases, but eventually their reserves are exhausted and they die (Colinet 2007). Furthermore, the consumption of lipids results in fewer individuals surviving, a reduction in the number of eggs in the ovaries of females and in the volume of the seminal vesicles and testicles of the males (Michel 2007).

The surviving adults clearly differ from the initial population in that they survived the cold, in other words, there has been a selection of certain individuals (Amice et al. 2008). This is why Ismail et al. (2010) measured the physiological cost of cold storage that do not result in death and do not involve selection. The treatments they used were 1 and 2 weeks at $7{ }^{\circ} \mathrm{C}$ with $S$. avenae as the host aphid. They record a decrease in lipid and water content of mummies after both treatments, and a reduction in the longevity of females that underwent the longer treatment. Male longevity and female fertility were not affected. Also, the use of a fluctuating temperature (i.e. the mummies were stored at $20^{\circ} \mathrm{C}$ for two hours, once every day) partially reduced the effects of cold storage.

To optimise the refrigeration of mass-produced parasitoids it is important to determine the best temperature at which to keep them and for how long. An optimal combination of these two parameters should permit a relatively long period of conservation, without undesired 
emergence of adults or loss of quality, in terms of survival and/or quality of the adults.

The objective is to improve the technique of conservation and storage of Aphidius ervi pupae that developed in two different species of aphid, Sitobion avenae and Acyrtosiphon pisum. The lower temperature threshold for development of $A$. ervi pupae in mummies is somewhere between 2.2 and $6.8^{\circ} \mathrm{C}$ (Sigsgaard 2000; Malina and Praslicka 2008) so the storage temperatures used were based on these estimates. A temperature of $7{ }^{\circ} \mathrm{C}$ should slow down the development of mummies and delay the emergence of the adult parasitoids. Mummies kept at a temperature of $2{ }^{\circ} \mathrm{C}$, on the other hand, should cease developing and no adults should emerge. The effect of storage can then be evaluated in terms of the longevity and fertility of the surviving females.

\section{Material and methods}

\section{Rearing of the aphids and parasitoid}

The aphids, Sitobion avenae and Acyrtosiphon pisum, were reared in the laboratory under controlled conditions $\left(20 \pm 1{ }^{\circ} \mathrm{C}, 60 \pm 10 \%\right.$ relative humidity, photoperiod $16: 8$ ). The host plants used were Triticum aestivum $L$. for S. avenae and Vicia faba L. for A. pisum.

The parasitoid Aphidius ervi was reared separately on each of the above hosts under the same controlled conditions as those used for the aphids. The females used for the experiments were 2-3 days old, mated and naive.

\section{Obtaining mummies for refrigeration}

To obtain the mummies that were to undergo the different treatments, synchronised second-stage $S$. avenae or A. pisum aphids were presented to female A. ervi for four hours, at $20^{\circ} \mathrm{C}$. Each mummy formed was then isolated when one day old and randomly assigned to a treatment $\left(20^{\circ} \mathrm{C}, 7^{\circ} \mathrm{C}\right.$ or $\left.2^{\circ} \mathrm{C}\right)$.

\section{Storage temperatures}

Each mummy was placed individually in a Petri dish (5.5 cm diameter), which contained cotton wool soaked in water and was hermetically sealed (100\% relative humidity). The dishes were placed in different incubators $\left(20^{\circ} \mathrm{C}, 7^{\circ} \mathrm{C}\right.$ and $2^{\circ} \mathrm{C}$ ) (directly, rather than via a progression of intermediate temperatures) in the dark, so that the time of emergence would not be biased by light/dark cycles (Mackauer and Henkelman 1975). There were at least 90 replicates of each treatment.

In the 20 and $7{ }^{\circ} \mathrm{C}$ treatments, the parasitoids emerged synchronously. Each day, the adult parasitoids that emerged were removed and sexed. No parasitoids emerged in the $2{ }^{\circ} \mathrm{C}$ treatment so every week for seven weeks several mummies (between 12 and 15) were re- moved from this incubator and placed at $20{ }^{\circ} \mathrm{C}$ and the emergence of adults monitored.

\section{Proportion of pupae that survived and the time it took them to complete their development}

For the 20 and $7{ }^{\circ} \mathrm{C}$ treatments, the time (in days) for the pupa in each mummy to complete its development was calculated as the time between mummy formation and adult emergence. For the $2{ }^{\circ} \mathrm{C}$ treatment, the temperature was theoretically lower than To, the threshold for mummy development, so that development did not resume until the mummy was moved to $20^{\circ} \mathrm{C}$ after 1 to 7 weeks. For this reason, the development time was calculated as the time between removal from the $2{ }^{\circ} \mathrm{C}$ incubator and the emergence of the adult at $20^{\circ} \mathrm{C}$.

Three weeks after the last emergence, the mummies in each batch from which no parasitoid had emerged were counted and dissected. The proportion that survived (or emerged) in each batch was obtained by expressing the number of parasitoids that emerged as a proportion of the total number of mummies stored.

\section{Size of the adults}

The length of the tibia of the third leg is the standard way of assessing the size of adult parasitoids (Godfray, 1994). For each adult that emerged, this measurement was obtained using a binocular microscope and a slide marked with graduations offering an accuracy of measurement of $0.001 \mathrm{~mm}$.

\section{Fertility}

One day old, virgin and naïve females were tested individually under the same conditions. Each of the $25 \mathrm{fe}$ males tested was placed in a patch of 50 similar aged aphids (the same species in which the parasitoid female was reared) at $20^{\circ} \mathrm{C}$. After 4 hours, the female was removed and the parasitized aphids were returned to plants. Three to 4 days later, the aphids were dissected to determine how many were parasitized.

\section{Longevity}

The longevity of female parasitoids kept without food was measured. The females were the ones that were used for determining fertility and they were kept in a Petri dish (5.5 cm diameter) at $20 \pm 1{ }^{\circ} \mathrm{C}$ and $100 \%$ relative humidity, in the dark.

\section{Statistical analyses}

For each species of host aphid, the proportion of mummies that survived (i.e. the proportion from which adults emerged) at 7 and $2{ }^{\circ} \mathrm{C}$ were compared with the proportion that emerged in the control $\left(20^{\circ} \mathrm{C}\right)$ using a $\chi^{2}$ 
test (PROC FREQ, SAS Institute). The Fisher's exact test value was calculated along with the associated probability.

Analysis of the size and development time of the mummies was done using a three-way ANOVA (PROC GLM, SAS Institute) with the aphid host species, parasitoid sex and the treatment $\left(20^{\circ} \mathrm{C}, 7^{\circ} \mathrm{C}\right.$ or $2^{\circ} \mathrm{C}$ from 1 to 7 weeks) as the principal factors. As the number of samples was not identical for all of the groups, the models were "unbalanced", so adjusted means (Least Squares Means) and Type III Sums of Squares were used. The normality was checked using the Shapiro-Wilk test (PROC UNIVARIATE, SAS Institute) and homoscedasticity using the Levene test (PROC GLM, SAS Institute). The multiple comparisons of means were carried out using the Tukey-Kramer method $(\alpha=0.05)$ to describe the differences between groups, and the Dunnett test $(\alpha=0.05)$ for comparison with the $20^{\circ} \mathrm{C}$ control.

The fertility of the females was transformed to a mean using an $\arcsin \sqrt{ }$ function. The analysis was completed using a two-way ANOVA (PROC GLM, SAS Institute) with the aphid host species and the treatment of the mummies $\left(20^{\circ} \mathrm{C}\right.$, 1 week at $7{ }^{\circ} \mathrm{C}$ or at $\left.2{ }^{\circ} \mathrm{C}\right)$ as the principal factors. The multiple comparisons of means were done using the Tukey test $(\alpha=0.05)$. The same method was used to analyze longevity, except that the results were not transformed. The results presented in the tables and figures are not transformed.

\section{Results}

\section{Proportion of pupae that survived and the time it took them to complete their development}

\section{a) Proportion that survived}

In the two control treatments $\left(\right.$ at $\left.20^{\circ} \mathrm{C}\right)$ the proportion that survived was greater than 0.9 . Moreover, the proportion of pupae in $S$. avenae mummies that survived was
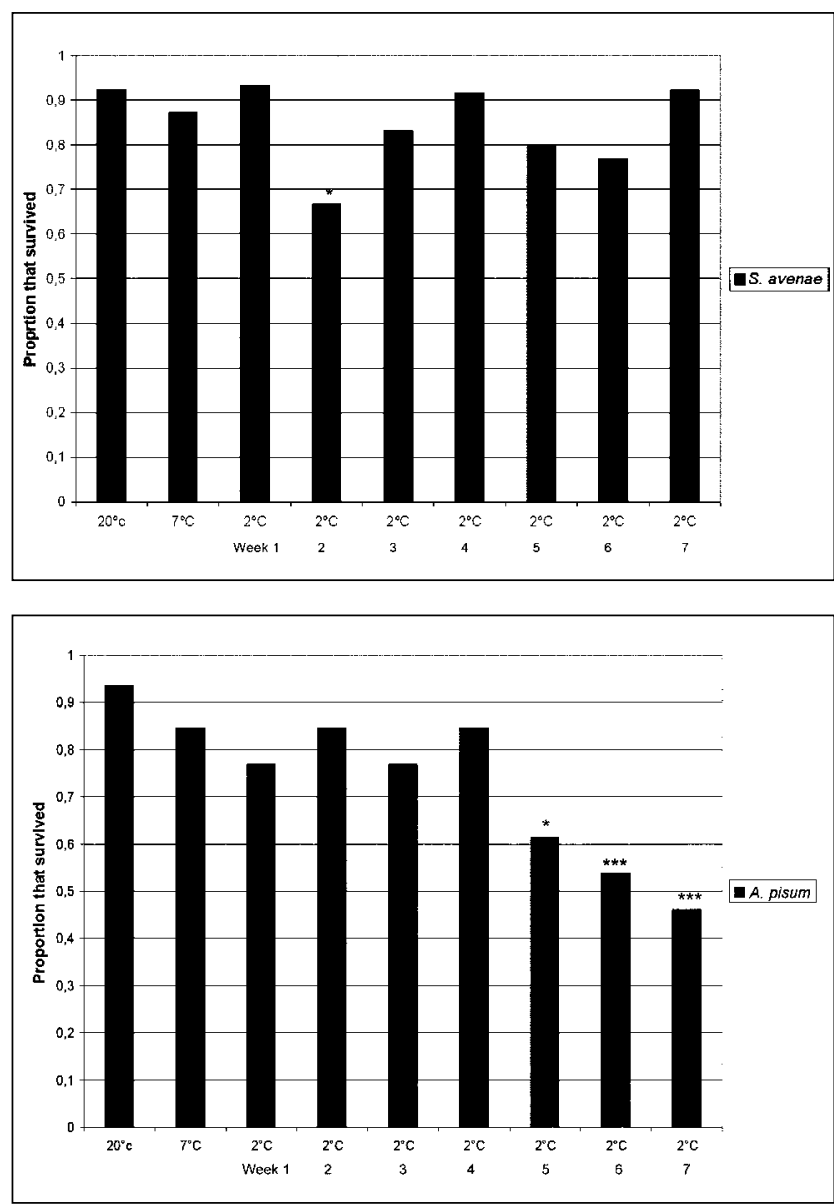

Fig. 1 Proportions of the mummies of the aphids S. avenae and A. pisum that survived in each treatment. Significant differences relative to the $20^{\circ} \mathrm{C}$ control are marked * (Fisher's exact test, $a=0.05$ ) and highly significant differences are marked *** (Fisher's exact test, $a=0.01$ ).

more than 0.8 regardless of treatment, even those which spent 7 weeks at $2{ }^{\circ} \mathrm{C}$ ( 0.92 survived). On the other hand, the proportion of pupae in mummies of $A$. pisum that survived decreased with each successive week when kept

Table 1 Proportion of mummies that survived in the different treatments $\left(20^{\circ} \mathrm{C}, 7^{\circ} \mathrm{C}, 2^{\circ} \mathrm{C}\right.$ for between 1 and 7 weeks), in each species of host aphid (S. avenae, A. pisum) and the number of mummies stored. $x^{2}$ test relative to the $20^{\circ} \mathrm{C}$ control: the Fisher's exact test value (Fisher p) and associated probability $(P)$.

Significant differences $(\alpha=0.05)$ are marked * and highly significant differences $(\alpha=0.01)$ are marked ***.

\begin{tabular}{|c|c|c|c|c|c|c|c|c|c|}
\hline \multirow{2}{*}{ S. avenae } & \multirow{2}{*}{$20^{\circ} \mathrm{C}$} & \multirow{2}{*}{$7^{\circ} \mathrm{C}$} & \multicolumn{7}{|c|}{$2^{\circ} \mathrm{C}$} \\
\hline & & & Week 1 & Week 2 & Week 3 & Week 4 & Week 5 & Week 6 & Week 7 \\
\hline No. of mummies & 93 & 86 & 15 & 12 & 12 & 12 & 15 & 13 & 13 \\
\hline Proportion that survived & 0.925 & 0.872 & 0.933 & $0.667 *$ & 0.833 & 0.917 & 0.800 & 0.769 & 0.923 \\
\hline $\mathrm{p}$ (Fisher) & - & 0.1009 & 0.4037 & 0.0188 & 0.2081 & 0.4077 & 0.1113 & 0.0851 & 0.4084 \\
\hline$P$ & - & 0.3211 & 1.0000 & 0.021 & 0.2732 & 1.0000 & 0.1426 & 0.1044 & 1.0000 \\
\hline \multirow{2}{*}{ A. pisum } & \multirow{2}{*}{$20^{\circ} \mathrm{C}$} & \multirow{2}{*}{$7^{\circ} \mathrm{C}$} & \multicolumn{7}{|c|}{$2^{\circ} \mathrm{C}$} \\
\hline & & & Week 1 & Week 2 & Week 3 & Week 4 & Week 5 & Week 6 & Week 7 \\
\hline No. of mummies & 94 & 85 & 13 & 13 & 13 & 13 & 13 & 13 & 13 \\
\hline Proportion that survived rate & 0.936 & 0.847 & 0.769 & 0.846 & 0.769 & 0.846 & $0.615^{*}$ & $0.538 * * *$ & $0.462 * * *$ \\
\hline $\mathrm{p}$ (Fisher) & - & 0.0309 & 0.0649 & 0.1948 & 0.0649 & 0.1948 & 0.0034 & 0.0006 & $<0.0001$ \\
\hline $\mathrm{P}$ & _- & 0.0869 & 0.0771 & 0.2502 & 0.0771 & 0.2502 & 0.0037 & 0.0006 & $<0.0001$ \\
\hline
\end{tabular}




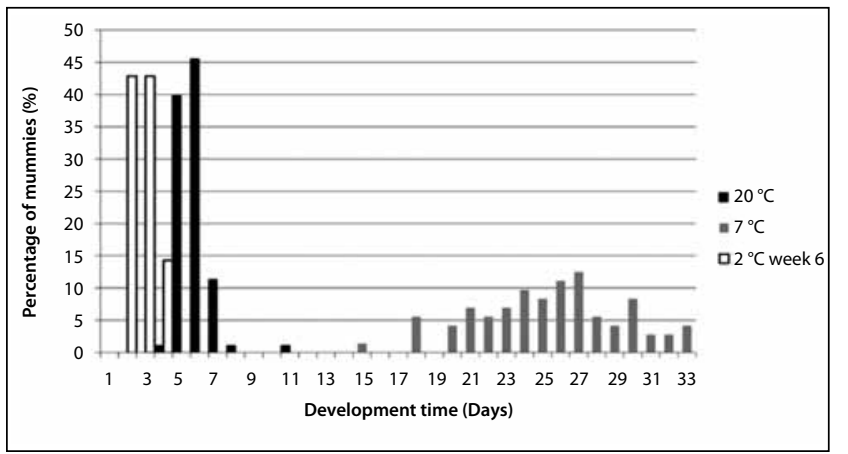

Fig. 2 Proportions of the parasitoids that emerged over time from mummies of $A$. pisum subjected to three different treatments: the development time of the pupae was the number of days between the "one day old mummy" stage and adult emergence in the $20^{\circ} \mathrm{C}$ and $7{ }^{\circ} \mathrm{C}$ treatments and the number of days between removal from the incubator and adult emergence for the treatment of 6 weeks at $2{ }^{\circ} \mathrm{C}$

at $2{ }^{\circ} \mathrm{C}$ : from 0.61 after 5 weeks, to 0.54 after 6 weeks and 0.46 after 7 weeks (Fig. 1, Table 1).

\section{b) Duration of development}

At $20^{\circ} \mathrm{C}$ and $7^{\circ} \mathrm{C}$, parasitoids emerged from the mummies spontaneously in the incubators. The histogram in Fig. 2 records the proportion of the mummies from which parasitoids emerged each day starting from the beginning of storage. The emergence of parasitoids from mummies in of $A$. pisum kept at $20^{\circ} \mathrm{C}$ (the control) was spread over about five days, reaching a maximum around the 5-6th day. At $7^{\circ} \mathrm{C}$, on the other hand, the emergences were more spread out, and occurred almost continually between day 15 and day 33 of storage. The average devel-
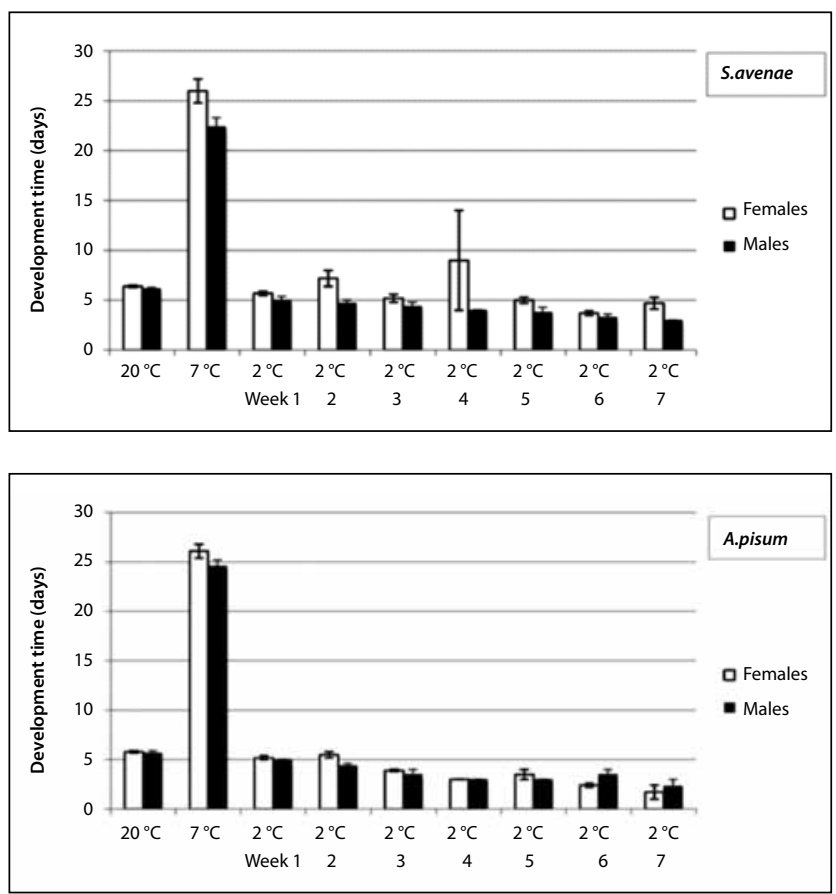

Fig. 3 Duration of development (in days: mean \pm SE) of pupae of females (white) and males (black) in the different to treatments $\left(20^{\circ} \mathrm{C}, 7^{\circ} \mathrm{C}, 2^{\circ} \mathrm{C}\right.$ for 1 to 7 weeks) and each of the two host species of aphid : S. avenae (top) and A. pisum (bottom). opment time of the pupae in the mummies (Fig. 3) was 6 days at $20^{\circ} \mathrm{C}$ (the control) and 24.8 days at $7^{\circ} \mathrm{C}$.

At $2{ }^{\circ} \mathrm{C}$, no parasitoids emerged during storage, even after seven weeks. The histogram in figure 2 shows that the emergence of parasitoids only started after the mummies were transferred to $20{ }^{\circ} \mathrm{C}$. This histogram is like that recorded for the control and is spread out over several days, but the parasitoids emerged sooner, especially if they had been stored for a long period. The average development time reflects these observations (Fig. 3, Table 2): it is shorter for the pupae in mummies stored at $2{ }^{\circ} \mathrm{C}$ for some time than in those which were kept continuously at $20^{\circ} \mathrm{C}$. The difference relative to the control mummies is more marked the longer they were stored at $2{ }^{\circ} \mathrm{C}$ and is significant after storage for 6 and 7 weeks (Dunnett test, table 2): in these two cases, the development time is around half that of the controls, as the parasitoids emerged from mummies, respectively, 3.2 and 2.9 days after being transferred from the $2{ }^{\circ} \mathrm{C}$ incubator, whilst the controls took 6 days. The effect of the "treatment" factor on development time is very significant in these cases $(F=430.78, P<0.0001)$. Moreover, it is the same regardless of host species or the sex of the parasitoid (interactions: aphid $^{\star}$ treatment: $\mathrm{F}=1.49, \mathrm{P}=0.1597$; treatment ${ }^{\star}$ sex: $\mathrm{F}=1.51, \mathrm{P}=0.1509$ ).

Furthermore, the pupae of female parasitoids took an average of one day longer to develop than those of males (Table 2). This difference is significant $(\mathrm{F}=4.20$, $\mathrm{P}=0.0410)$ and is depicted in Fig. 3. It should also be noted that the development of pupae in mummies of $S$. avenae requires, on average, one day longer than those in mummies of $A$. pisum (Table 2) and that this difference is significant $(\mathrm{F}=3.87, \mathrm{P}=0.0500)$. These sex and host aphid effects are additive (interaction: aphid $^{\star}$ sex: $\mathrm{F}=2.62, \mathrm{P}=0.1065)$.

Finally, the Levene test indicated heteroscedasticity among the treatments, meaning that the variances were not equal from one treatment to the next. As few mummies were stored at $2{ }^{\circ} \mathrm{C}$ (between 12 and 15 mummies) and sometimes the pupae in many of them died, which reduced the size of certain groups and decreased the accuracy of the measurements. However, for the $7^{\circ} \mathrm{C}$ group, in which there were more mummies, the variance was greater than in the other treatments. This may be due to the high variability in the time to emergence recorded at this temperature; emergences were spread over 15 days (Fig. 2). As the times to emergence at $7^{\circ} \mathrm{C}$ were more spread out than they were at $20^{\circ} \mathrm{C}$ the development time is more variable.

\section{Size, fertility and longevity of the females that emerged from the mummies}

The length of the tibia of parasitoids that emerged from mummies of $A$. pisum $(0.8 \mathrm{~mm})$ is significantly longer than that of parasitoids that emerged from mummies of $S$. avenae $(0.55 \mathrm{~mm})(\mathrm{F}=802.87, \mathrm{P}<0.0001)$. 
Table 2 Three-way ANOVA of the time is takes the pupae to develop (in days), with the two species of host aphid (S. avenae, A. pisum), the different treatments $\left(20^{\circ} \mathrm{C}, 7^{\circ} \mathrm{C}, 2^{\circ} \mathrm{C}\right.$ for between 1 and 7 weeks) and sex (female, male) as principal factors.

In each line, the means followed by a different letter are different (Tukey test, $a=0.05$ ).

The means marked ${ }^{*}$ are different from those of the $20^{\circ} \mathrm{C} \mathrm{control} \mathrm{(Dunnett} \mathrm{test,} a=0.05$ ).

\begin{tabular}{|c|c|c|c|c|c|c|c|c|c|c|c|c|}
\hline \multirow{3}{*}{ Aphid } & \multicolumn{3}{|c|}{ ANOVA 2} & \multicolumn{9}{|c|}{ Tukey / Dunnett's tests } \\
\hline & \multirow{2}{*}{$\frac{\mathrm{ddl} 1}{\mathrm{ddl}}$} & \multirow{2}{*}{$\frac{F 3.87}{F}$} & \multirow{2}{*}{$\frac{P 0.0500}{P}$} & \multicolumn{2}{|c|}{ S. avenae $7.2 \mathrm{a}$} & \multicolumn{7}{|c|}{ A. pisum 6.2 b } \\
\hline & & & & $20^{\circ} \mathrm{C}$ & $7^{\circ} \mathrm{C}$ & $2{ }^{\circ} \mathrm{C}$ & $2{ }^{\circ} \mathrm{C}$ & $2{ }^{\circ} \mathrm{C}$ & $2{ }^{\circ} \mathrm{C}$ & $2{ }^{\circ} \mathrm{C}$ & $2{ }^{\circ} \mathrm{C}$ & $2{ }^{\circ} \mathrm{C}$ \\
\hline \multirow{2}{*}{ Treatment } & & & & Control & & Week 1 & Week 2 & Week 3 & Week 4 & Week 5 & Week 6 & Week 7 \\
\hline & 8 & 430.78 & $<0.0001$ & 6.0 & $24.8^{*}$ & 5.2 & 5.4 & 4.2 & 4.8 & 3.8 & $3.2^{*}$ & $2.9^{*}$ \\
\hline \multirow{2}{*}{ Sex } & ddl & $\mathrm{F}$ & $\mathrm{P}$ & Female & & & & Male & & & & \\
\hline & 1 & 4.20 & 0.0410 & $7.2 \mathrm{a}$ & & & $6.2 \mathrm{~b}$ & & & & & \\
\hline \multirow{2}{*}{ Aphid* Sex } & ddl & $\mathrm{F}$ & $\mathrm{P}$ & & & & & & & & & \\
\hline & 1 & 2.62 & 0.1065 & & & & & & & & & \\
\hline \multirow{2}{*}{ Aphid* Treatment } & ddl & $\mathrm{F}$ & $P$ & & & & & & & & & \\
\hline & 8 & 1.49 & 0.1597 & & & & & & & & & \\
\hline \multirow{2}{*}{ Treatment* Sex } & ddl & $\mathrm{F}$ & $\mathrm{P}$ & & & & & & & & & \\
\hline & 8 & 1.51 & 0.1509 & & & & & & & & & \\
\hline \multirow{2}{*}{ Aphid* Treatment *Sex } & ddl & $\mathrm{F}$ & $\mathrm{P}$ & & & & & & & & & \\
\hline & 8 & 0.41 & 0.9133 & & & & & & & & & \\
\hline
\end{tabular}
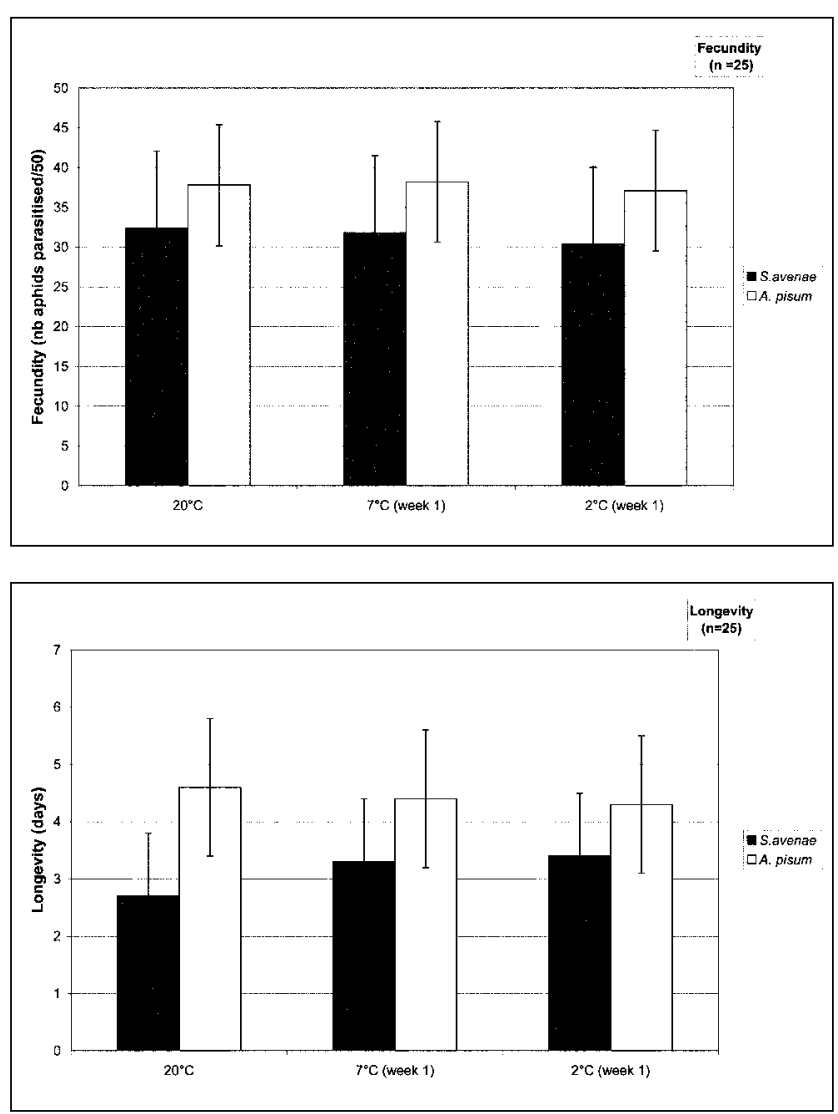

Fig. 4 The number of aphids parasitized out of 50 and longevity (in days; mean $\pm \mathrm{SE}$ ) of females that emerged from mummies of S. avenae and A. pisum stored at either $20^{\circ} \mathrm{C}$ (control), 1 week at $7{ }^{\circ} \mathrm{C}$ or at $2{ }^{\circ} \mathrm{C}$

The average fertility and longevity of females are presented in Fig. 4, according to host aphid and thermal treatment. Neither was affected by exposure to $2{ }^{\circ} \mathrm{C}$ or $7^{\circ} \mathrm{C}$ (fertility: $\mathrm{F}=0.41, \mathrm{P}=0.6626 ;$ longevity: $\mathrm{F}=0.37$,
$\mathrm{P}=0.6929$ ) (Table 3). On the other hand, both were affected very significantly by the host species (fertility: $\mathrm{F}=19.02, \mathrm{P}<0.0001$; longevity: $\mathrm{F}=41.19, \mathrm{P}<0.0001$ ) (Table 3), with the females that emerged from A. pisum mummies the most fertile and long lived. These females parasitized an average 37.7 of 50 aphids and lived, on average, 4.4 days, whilst those that emerged from S. avenae mummies only parasitized an average 31.6 aphids and lived just 3.1 days (Fig. 1, Table 1). This was recorded in all treatments (fertility: interaction: $\mathrm{F}=0.07, \mathrm{P}=0.9366$; longevity: interaction: $\mathrm{F}=2.17, \mathrm{P}=0.1177$ ) (Table 3 ).

Table 3 Two-way ANOVA of female fertility (number of aphids parasitized out of 50) and their longevity (in days) when reared in each of the host aphids (S. avenae, A. pisum) and in different treatments $\left(20^{\circ} \mathrm{C}, 1\right.$ week at $7{ }^{\circ} \mathrm{C}, 1$ week at $\left.2^{\circ} \mathrm{C}\right)$.

In each line, the averages followed by a different letter are different (Tukey test, $a=0.05$ ).

\begin{tabular}{|c|c|c|c|c|c|}
\hline \multicolumn{6}{|l|}{ Fecundity } \\
\hline & & ANOV & & Tuke & test \\
\hline \multirow{2}{*}{ Aphid } & ddl & $\mathrm{F}$ & $\mathrm{P}$ & S. avenae & A. pisum \\
\hline & 1 & 19.02 & $<0.0001$ & $31.6 \mathrm{~b}$ & $37.7 \mathrm{a}$ \\
\hline \multirow{2}{*}{ Treatment } & ddl & $\mathrm{F}$ & $\mathrm{P}$ & & \\
\hline & 2 & 0.41 & 0.6626 & & \\
\hline Aphid* & ddl & $\mathrm{F}$ & $\mathrm{P}$ & & \\
\hline Treatment & 2 & 0.07 & 0.9366 & & \\
\hline \multicolumn{6}{|l|}{ Longevity } \\
\hline & \multicolumn{3}{|c|}{ ANOVA 2} & \multicolumn{2}{|c|}{ Tukey's test } \\
\hline \multirow{2}{*}{ Aphid } & ddl & $\mathrm{F}$ & $\mathrm{P}$ & S. avenae & A. pisum \\
\hline & 1 & 41.19 & $<0.0001$ & $3.1 \mathrm{~b}$ & $4.4 \mathrm{a}$ \\
\hline \multirow{2}{*}{ Treatment } & ddl & $\mathrm{F}$ & $\mathrm{P}$ & & \\
\hline & 2 & 0.37 & 0.6929 & & \\
\hline Aphid* & ddl & $\mathrm{F}$ & $\mathrm{P}$ & & \\
\hline Treatment & 2 & 2.17 & 0.1177 & & \\
\hline
\end{tabular}


The fertility and longevity of female A. ervi were not decreased when the mummies were stored for one week at $7{ }^{\circ} \mathrm{C}$ or $2{ }^{\circ} \mathrm{C}$, but the average fertility and longevity of those that emerged from $A$. pisum mummies were greater than those that emerged from $S$. avenae mummies.

\section{Discussion and conclusions}

\section{Proportion of the pupae in mummies that survived}

The survival of $A$. ervi females seemed not to be affected by exposure to $7^{\circ} \mathrm{C}$ during mummy development. However, whilst the $S$. avenae mummies survived storage at $2{ }^{\circ} \mathrm{C}$, even when it lasted seven weeks, those of A. pisum died from week 5 onwards. Generally, smaller individuals suffer more when exposed to low temperatures, which may be, for example, because they have lower reserves (Colinet 2007) or because their bodies have a higher surface area for evaporation relative to their volume (Legrand 2005). As for this experiment, $A$. pisum is a bigger aphid than $S$. avenae and the individuals that emerged from mummies of the former species were also larger.

The survival recorded at $2{ }^{\circ} \mathrm{C}$ is surprising viewed in light of our current knowledge of $A$. ervi. Indeed, Michel (2007) also stored mummies of $A$. ervi raised on A. pisum at $2{ }^{\circ} \mathrm{C}$, for periods of 1,2 and 3 weeks, and recorded percentage survival, respectively, of $85 \%, 63 \%$ and $41 \%$. The results presented, on the other hand, were $77 \%, 85 \%$ and $77 \%$, respectively, for the same lengths of time at $2{ }^{\circ} \mathrm{C}$. The high humidity in the Petri dishes allowed the mummies to survive, whilst in Michel (2007) study the mummies desiccated in the drier environment he used. This is also indicated by Levie's results (2002) with Aphidius rhopalosiphi: the percentage emergence peaked after three weeks of storing the mummies at $3{ }^{\circ} \mathrm{C}$ and $\geq 80 \%$ humidity, whilst at a humidity level of $30 \%$, the percentage emergence declined from the second week onwards.

Thus, survival was not reduced by storage at $7{ }^{\circ} \mathrm{C}$, or after 7 weeks at $2{ }^{\circ} \mathrm{C}$ when $S$. avenae was the host, or 4 weeks when A. pisum was the host. High humidity seems to be important for consistently high percentages of emergence.

\section{Duration of the development of the pupae in mummies}

The pupae developed more slowly at $7{ }^{\circ} \mathrm{C}$ than at $20^{\circ} \mathrm{C}$. This phenomenon can be explained by the sum of effective temperatures concept: in cold conditions, temperatures accumulate more slowly, resulting in a longer duration of development. The average developmental time was 6 days at $20^{\circ} \mathrm{C}$ and of 24.8 days at $7^{\circ} \mathrm{C}$. Based on the estimates of the lower temperature threshold for development and the sum of effective temperatures cited in the literature on A. ervi, the development time should have been 5.4 days at $20^{\circ} \mathrm{C}$ and 182.5 days at $7{ }^{\circ} \mathrm{C}$ (Sigs- gaard 2000), or 5.3 days at $20^{\circ} \mathrm{C}$ and 27.5 days at $7{ }^{\circ} \mathrm{C}$ (Malina and Praslicka 2008). However, caution must be exercised when comparing the present results with those of previous studies: the geographic origins of the parasitoids (here, Denmark and Slovakia) differ and therefore adaptations to the temperatures prevailing in different countries could result in different estimates (Campbell et al. 1974; Morgan et al. 2001).

Moreover, emergence in time at $7^{\circ} \mathrm{C}$ was more spread out than at $20^{\circ} \mathrm{C}$, and the duration of development at $7{ }^{\circ} \mathrm{C}$ was more variable. This may be easily explained by the sum of effective temperatures concept as the same variation in degree-days represents more days at low temperatures. For example, the accumulation of enough heat to equal a $42{ }^{\circ} \mathrm{C}$ day takes 2.1 days at $20^{\circ} \mathrm{C}$ and 6 days at $7{ }^{\circ} \mathrm{C}$. The emergence in time at $7^{\circ} \mathrm{C}$ is therefore more spread out than at $20^{\circ} \mathrm{C}$ because of the lower temperature. Development at $7{ }^{\circ} \mathrm{C}$ therefore modifies the mean and variance of the development time (in days).

Furthermore, no emergence was recorded during storage at $2{ }^{\circ} \mathrm{C}$. This was expected as this temperature is hypothetically lower than To, the threshold below which pupae do not develop (a To $=6.6{ }^{\circ} \mathrm{C}$ is cited by Sigsgaard 2000 and a To $=3.9^{\circ} \mathrm{C}$ by Malina and Praslicka 2008). Nevertheless, when the mummies were transferred to $20{ }^{\circ} \mathrm{C}$ after 1 to 7 weeks, the developmental time was expected to be identical to that of the controls, since development is assumed to have ceased during the period they were stored at $2{ }^{\circ} \mathrm{C}$, which is lower than To. However, the mummies did develop to some extent at $2{ }^{\circ} \mathrm{C}$, accumulating some degree days under these conditions, which is why they emerged slightly earlier than the mummies which had not been stored at $2{ }^{\circ} \mathrm{C}$. This was most noticeable when the period of storage was long. These observations indicate that the estimate of To obtained using a linear extrapolation is too high because the relationship is curvilinear and so at $2{ }^{\circ} \mathrm{C}$ development is slow but not completely stopped. This conclusion was also reached by Colinet (2007) working with Aphidius colemani.

The duration of development of the parasitoids that emerged from $A$. pisum mummies was shorter than that of those that emerged from $S$. avenae mummies; protandry was also greater for the former.

Mummies can therefore be stored at $7{ }^{\circ} \mathrm{C}$ for a maximum of 2 weeks, after which adult parasitoids will start to emerge.

\section{Fertility and longevity of the parasitoids}

The results reported here for longevity (averages of 3.1 days and 4.4 days) are similar to the results of Azzouz et al. (2004) and Ismail et al. (2010) who cite life spans of, respectively, 3.7 and 2.95 days for female $A$. ervi deprived of food.

Furthermore, the 50 aphids exposed to parasitisation by the recently emerged females exceeds the number 
that A. ervi can parasitize in 4 hours (Colinet et al. 2005) but sufficient to reveal differences in fertility. Females of A. ervi are pro-synovigenic, i.e., they emerge from the mummy with mature eggs in their ovaries and continue to produce eggs throughout their adult lives ( $\mathrm{He}$ and Wang 2008). Given that a surplus of aphids were provided to each female, the number of eggs laid during the first day of the female's adult life is a measure of the stock of eggs present at the time of emergence, and thus, approximately, a measure of the quantity of resources present in the larva that were allocated to reproduction (Sequeira and Mackauer 1994). In addition, each female has in her body resources in the form of lipid reserves, which enable her to survive without food. The longevity of the females can be used as an estimate of the size of this resource.

The females that emerged from A. pisum mummies were fitter than those from $S$. avenae mummies in terms of their fertility and longevity. This confirms that the size of the aphid host determines the quantity of resource available to the parasitoid, which in turn determines its length of life and the number of mature eggs in its ovaries at emergence. The higher percentage mortality of the parasitoids from A. pisum mummies compared to those from $S$. avenae mummies may be consequence of the smaller individuals that emerged from the A. pisum mummies had fewer lipid reserves and as a result were the first to die and the least fertile.

Another possible explanation is that the aphid host is the same species as that in which the parasitoid was raised. The higher fecundity of females that emerged from A. pisum mummies could, therefore, be due more to the female's general preference for $A$. pisum over S. avenae. Indeed, according to Daza-Bustamante (2003), A. pisum is more often attacked by A. ervi than S. avenae, probably because of its larger size or its more yellow colour and attractive odour (Battaglia et al. 2000), or because this aphid is more active (the movements of aphids stimulate oviposition) (Mackauer et al. 1996).

To determine whether the attack rate is determined by the origin of the female or the species of aphid provided, the same species of aphid could have been offered to all of the females, whether they emerged from A. pisum or $S$. avenae. However, this would have created a bias in favour of females reared on the species of aphid chosen for the fertility test. Indeed, Pungerl (1984) suggests that A. ervi is conditioned to recognise and prefer the host on which it was reared. For this reason, a third species of host aphid, such as Myzus persicae, should have been used for the fertility test, regardless of the original host aphid, and so avoid creating a bias due to preference.

In addition, neither the fertility nor the longevity of the females seemed to be decreased after being exposed for 1 week to temperatures of $7{ }^{\circ} \mathrm{C}$ or $2{ }^{\circ} \mathrm{C}$. However, in the absence of food, survival is entirely dependent on the internal reserves (Ellers 1996) accumulated up until the end of the last larval stage (death of the host and weav- ing of the cocoon) (Sequeira and Mackauer 1994). Starvation during storage is likely to lead to a reduction in these reserves (Colinet et al. 2007). Storage for one week, therefore, probably is not long enough to result in a significant reduction in lipid reserves. Ismail et al. (2010) observed the same results after one week at $7{ }^{\circ} \mathrm{C}$, although the longevity of females was reduced by one third after two weeks at $7{ }^{\circ} \mathrm{C}$. Michel (2007) also records a decrease in the number of eggs in the ovaries when mummies are kept at $0{ }^{\circ} \mathrm{C}$ for 2 weeks.

These experiments show that the host of the parasitoid is an important consideration when determining the optimal conditions for conserving mummies. However, the mass production of mummies containing $A$. ervi can be facilitated by storing them for several weeks. In such cases, it is also advantageous to store the mummies at both 7 and $2{ }^{\circ} \mathrm{C}$ before mass release as then a single application results in a staggered emergence of adults over a longer period of time and thus efficient control for longer.

\section{REFERENCES}

Amice G, Vernon P, Outreman Y, Van Alphen J, Van Baaren J (2008) Variability in responses to thermal stress in parasitoids. Ecol Ent 33: 701-708.

Azzouz H, Giordanengo P, Wackers FL, Kaiser L (2004). Effects of feeding frequency and sugar concentration on behavior and longevity of the adult aphid parasitoid: Aphidius ervi (Haliday) (Hymenoptera: Braconidae). Biol Control 31: 445-452.

Battaglia D, Poppy G, Powell W, Romano A, Tranfaglia A, Pennacchio F (2000) Physical and chemical cues influencing the oviposition behavior of Aphidius ervi. Ent Exp Appl 94: 219-227.

Campbell A, Frazer BD, Gilbert N, Gutierrez AP, Mackauer M (1974) Temperature requirements of some aphids and their parasites. J Appl Ecol 11: 431-438.

Colinet H, Salin C, Boivin G, Hance T (2005) Host age and fitness-related traits in a koinobiont aphid parasitoid. Ecol Ent 30: 473-479.

Colinet H, Hance T, Vernon P (2006) Water relations, fat reserves, survival, and longevity of a cold-exposed parasitic wasp Aphidius colemani (Hymenoptera: Aphidiinae). Env Ent 35: 228-236.

Colinet H (2007) Une approche écologique et biochimique de la résistance au froid chez un parasitoïde de puceron Aphidius colemani (Hymenoptera : Aphidiiinae). PhD Thesis, Université Catholique de Louvain, Louvain-la-Neuve.

Daza-Bustamante P, Fuentes-Contreras E, Niemeyer HM (2003) Acceptance and suitability of Acyrtosiphon pisum and Sitobion avenae as hosts of the aphid parasitoid Aphidius ervi (Hymenoptera: Braconidae). Eur J Ent 100: 49-53.

Ellers J, Driessen G, Sevenster JG (2000) The shape of the trade-off function between egg production and life span in the parasitoid Asobara tabida. Neth J Zool 50: 29-36.

Godfray HCJ (1994) Parasitoids. Behavioral and evolutionary ecology. Princeton University Press, New Jersey.

He XZ, Wang Q (2008) Reproductive strategies of Aphidius ervi Haliday (Hymenoptera: Aphidiidae). Biol Control 45: 281-287.

Ismail M, Vernon P, Hance T, van Baaren J (2010) Physological cost of cold exposure on the parasitoid Aphidius ervi, without selection pressure and under constant or fluctuating temperatures. BioControl 55: 729-740. 
Langer A, Hance T (2000) Overwintering strategies and cold hardiness of two aphid parasitoid species (Hymenoptera: Braconidae: Aphidiinae). J Insect Physiol 46: 671-676.

Langer A, Boivin G, Hance T (2004) Oviposition, flight and walking capacity at low temperatures of four aphid parasitoid species (Hymenoptera: Aphidiinae). Eur J Ent 101: 473-479.

Legrand MA (2005) Overwintering strategies of the parasitoid Aphidius rhopalosiphi DeStefani-Perez (Hymenopter: Aphidiinae). $\mathrm{PhD}$ Thesis, Université Catholique de Louvain, Louvain-la-Neuve.

Levie A (2002) Develoment of a biological control method of wheat aphids, by using Aphidiinae parasitoids (Hymenoptera: Braconidae). PhD Thesis. Université Catholique de Louvain, Louvain-la-Neuve.

Mackauer M, Henkelman DH (1975) Effect of light-dark cycles on adult emergence in the aphid parasite Aphidius smithi. Can J Zool 53(9): 1201-1206.

Mackauer M, Michaud JP, Volkl W (1996) Host choice by aphidiid parasitoids (Hymenoptera: Aphidiidae): host recognition, host quality and host value. Can Ent 128: 959-980.

Malina R, Praslicka J (2008) Effect of temperature on the developmental rate, longevity and parasitism of Aphidius ervi Haliday (Hymenoptera: Aphidiidae). Plant Protect Sci 44: 19-24.
Michel C (2007) Etude générale de l'impact du froid sur la survie et la morphologie du système reproducteur d'Aphidius ervi (Hymenoptera : Aphidiinae). Mémoire de fin détude, Université Catholique de Louvain, Louvain-la-Neuve.

Morgan D, Walters KFA, Aegerter JN (2001) Effect of temperature and cultivar on pea aphid, Acyrthosiphon pisum (Hemiptera: Aphididae) life history. Bull Ent Res 91: 47-52.

Pungerl NB (1984) Host preferences of Aphidius (Hymenoptera: Aphidiidae) populations parasitising pea and cereal aphids (Hemiptera: Aphididae). Bull Ent Res 74: 153-161.

SAS Institute (2004) SAS/STAT user's guide, release 9.1. SAS Institute Inc., Cary, NC.

Sequeira R, Mackauer M (1994) Variation in selected life-history parameters of the parasitoid wasp, Aphidius ervi: influence of host developmental stage. Ent Exp Appl 71: 15-22.

Sigsgaard L (2000) The temperature-dependent duration of development and parasitism of three cereal aphid parasitoids, Aphidius ervi, A. rhopalosiphi, and Praon volucre. Ent Exp Appl 95: 173-184.

Stilmant D, Van Bellinghen C, Hance T, Boivin G (2008). Host specialization in habitat specialists and generalists Oecologia 156: 905-912. 